\title{
Effect of food intake and ambient air pollution exposure on ankylosing spondylitis disease activity
}

\author{
Narjes Soleimanifar ${ }^{1,2,3}$, Mohammad Hossein Nicknam ${ }^{1,3}$, Katayoon Bidad ${ }^{4}$, Ahmad Reza Jamshidi ${ }^{5}$, \\ Mahdi Mahmoudi ${ }^{5}$, Shayan Mostafaei ${ }^{6}$, Zahra Hosseini-khah ${ }^{2}$ and Behrouz Nikbin ${ }^{1,2,3^{*}}$
}

\begin{abstract}
Background: Ankylosing spondylitis (AS) is a chronic inflammatory disease characterized by axial arthritis. The genetic-environmental factors seem to be involved in the pathogenesis of the disease and the disease debilitates patients during the most productive stages of their lives. The aim of this study was to examine the relationships between two environmental factors, diet and air pollution with disease activity and functional impairment in AS.

Methods: A case-control study was carried out. Thirty patients with AS and 30 age and sex-matched healthy controls were included. Disease scores including BASMI, BASDAI, BASFI, and BASG were calculated by means of the international Ankylosing Spondylitis Assessment working group consensus recommendations. The food intake was evaluated by semiquantitative food frequency questionnaire (147 items FFQ). Level of air pollution indices, PM10 and PM2.5 information was obtained from the Tehran air quality control network.
\end{abstract}

Results: Total energy and fat intake, some vitamins (A, B1, B2, C) and mineral intake (potassium, calcium, iron, phosphorus, magnesium, zinc, copper and selenium) were significantly higher in patients with AS compared to controls. Fat component consumption especially Saturated Fat of Food was moderately correlated with BASFI score. PM2.5 long term exposure was strongly correlated with BASMI, BASFI and BASDAI scores of patients.

Conclusion: High-fat diet and long term exposure to air pollution are associated with worse disease outcomes reported in patients with AS. This is an interesting area of investigation in AS pathogenesis and management.

Keywords: Diet, Food intake, PM10, PM2.5, Air pollution, Ankylosing spondylitis

\section{Introduction}

Ankylosing spondylitis (AS) is a chronic progressive inflammatory disease among adults and is classified as an immune-mediated inflammatory rheumatic disease grouped under the term spondyloarthritis. It mainly Involves the axial skeleton including back, neck, or the sacroiliac joints $[1,2]$. AS is often associated with physical impairments due to decreased spinal mobility and can lead to early mortality.

The Globally mean prevalence of AS per 10,000 is reported to be 16.7 in Asia, 10.2 in Latin America, 31.9 in North America, 23.8 in Europe, and 7.4 in Africa [3].

\footnotetext{
* Correspondence: bnik33@hotmail.com; dnik@ams.ac.ir

${ }^{1}$ Molecular immunology research center, Tehran University of Medical Sciences, Tehran, Iran

${ }^{2}$ Department of Molecular Medicine, School of Advanced Technologies in Medicine, Tehran University of Medical Sciences, Tehran, Iran Full list of author information is available at the end of the article
}

Disease activity in AS patients differs extensively, i.e., some patients have only minimal symptoms whilst others suffer from an aggressive and widespread disease which can rapidly lead to severe disability. It has been suggested that this heterogeneity can be explained by genetic factors as well as environmental factors [4-6]. Air pollution and nutrition are amongst the two crucial environmental issues that can affect this disease.

Recently, the World Health Organization (WHO) cited exposure to outdoor urban air pollution (14th) among the top 15 risk factors for the Global Burden of Disease (WHO 2009) [7]; There is a growing interest on the role of air pollution, especially particulate matter (PM), on inflammation and diseases. Sources of PM are mostly from human activities and include industrial emissions and road vehicles. Particles come in a wide range of

(c) The Author(s). 2019 Open Access This article is distributed under the terms of the Creative Commons Attribution 4.0 International License (http://creativecommons.org/licenses/by/4.0/), which permits unrestricted use, distribution, and 
sizes. Particles less than or equal to $10 \mu \mathrm{m}$ in diameter (PM 10) are so small that they can get into the lungs, potentially causing serious health problems. Especially when fine PM with a median diameter $<2.5 \mu \mathrm{m}$ (PM 2.5) enter the body through airways, it can trigger a systemic inflammatory response $[8,9]$.

Nutritional habits and food intakes can also be involved in both promoting and combating inflammatory processes. Some evidence shows correlations between nutrients and induction of chronic inflammatory diseases. Excessive energy intake stimulates adipose cell growth and proliferation, hence promotes abdominal obesity, increasing the risk of diabetes, metabolic syndrome and other chronic diseases [10,11].We conducted the present study to evaluate relations between these two environmental risk factors, urban air pollution exposures and food intakes with disease activity of AS patients.

\section{Methods}

\section{Patients and controls}

Thirty patients with AS, diagnosed based on modified New York criteria [12], and 30 healthy age- and sex-matched controls were included. Patients with AS were recruited from the Iranian Ankylosing Spondylitis Association and healthy controls were employees of Tehran University of Medical Sciences. A questionnaire on disease information, medications, and demographic data was completed. $[13,14]$. BASDAI and BASFI are recommended by the international Ankylosing Spondylitis Assessment working group consensus [15], in the clinical evaluation of patients with AS and have been shown to be specific to the disease and sensitive to change [16]. We examined possible confounders by age and race, and to control for smoking, we calculated pack-years for the whole life of each participant (number of packs/day multiplied by number of years of cigarette smoking) and current smoking status (current/former/ never). The patients which had used biological drugs like TNF blockers were excluded because it as a confounding factor could mask clinical score of disease.

The study protocol was approved by the ethics board of Tehran University of Medical Sciences and written informed consent was obtained from all participants after explaining the research protocol to them.

\section{Food intake}

Food intake was evaluated by semi-quantitative food frequency questionnaire (147 items FFQ). Energy (kcal), carbohydrates (g), lipids (g), proteins (g), cholesterol mg/ $\mathrm{dl}$, fiber (g) and micronutrients were measured through the software N4. All anthropometric and food intake assessments were conducted by one expert in order to minimize the possible errors.

\section{Measures of ambient PM2.5 and PM10 levels}

Hourly measurements at fixed-site monitoring stations in Tehran were obtained from the Tehran air quality control network ( http://air.tehran.ir/ ). We assigned a concentration from the operational monitor closest to the area of residence of each participant within $10 \mathrm{~km}$ each day. Hourly PM2.5 and PM10 concentrations were recorded across all Tehran stations; these mean hourly levels, averaged for the day of all subjects' clinical evaluations, the previous week, the previous month and the previous 3 months. In the case of an incomplete series, each missing value was imputed by using an algorithm that integrates the annual average of the incomplete series and the PM concentrations of the nearest and more correlated monitors.

\section{Statistical analysis}

All analyses were performed by SPSS 20.0 software. All variables were examined by 1-sample Kolmogorov-Smirnov test to test their normal distribution. Parametric variables were described by mean \pm SD and nonparametric variables by median (range). Independent-sample t-test was used to compare means between parametric variables and the Mann-Whitney U test used to determine relationships between smoking with BASDAI and BASFI scores. Correlation analysis was performed using the Pearson and Spearman correlation coefficient for parametric and non-parametric variables, respectively. A value of $p<0.05$ was considered statistically significant.

\section{Results}

\section{Patients and controls}

Thirty patients with AS (24 men, 6 women) with a mean age of $35 \pm 10$ years and 30 age-matched and sex-matched healthy controls with a mean age of $33 \pm 8$ years were included in the study. $13(43 \%)$ patients and $9(30 \%)$ healthy controls were smokers and in the patient's group, there were no significant differences between smokers and nonsmokers regarding BASMI, BASFI and BASDAI score. The mean body mass index (BMI) was $21.73( \pm 3.14) \mathrm{kg} /$ $\mathrm{m}^{2}$ and $21.61( \pm 3.23) \mathrm{kg} / \mathrm{m}^{2}$ in the AS group and healthy group, respectively without significant differences $(p>$ $0.05)$. Mean disease duration was $10( \pm 7)$ years and BMI was weakly correlated to disease duration in patients group $(\mathrm{r}=0.36 ; p=0.049)$. Of the patients studied, 22 (73.3\%) were using non-steroidal anti-inflammatory drugs (NSAIDs)or disease-modifying anti-rheumatic drugs (DMARDs) or both, none were using corticosteroids or biological DMARDs and 8 (26.7\%) patients were not using any drugs. The characteristics of patients are shown in Table 1.

The mean caloric consumption was $2061.66( \pm 751)$ Kcal in AS group vs. 1652.18( \pm 551$)$ Kcal in healthy group $(p=0.028)$ and the mean of total fat intake was 
Table 1 Demographic characteristics of AS patients and controls

\begin{tabular}{lll}
\hline & Cases & Controls \\
\hline Numbers & 30 & 30 \\
Age (yrs) (SD) & $35.4(10.1)$ & $33.4(8.1)$ \\
BMI (kg/cm²) (SD) & $21.7(3.1)$ & $21.6(3.2)$ \\
Smoking status N (\%) & & \\
$\quad$ smoker & $13(43 \%)$ & $9(30 \%)$ \\
$\quad$ Non-smoker & $17(57 \%)$ & $21(70 \%)$ \\
Cigarette (pack/year) (SD) & $2.6(3.5)$ & $-2(5.2)$ \\
Disease duration (yrs) (SD) & $10.7(6.7)$ & - \\
BASDAl score (SD) & $4.02(2.3)$ & - \\
BASFI Score(SD) & $3.33(2.6)$ & - \\
BASMI Score (SD) & $3.38(2.0)$ & \\
BASG Score (SD) & $4.06(2.6)$ & \\
Treatment N (\%) & & \\
$\quad$ NSAID & $10(33.3 \%)$ & \\
DMARD & $2(6.7 \%)$ & \\
NSAID+DMARD & $10(33.3 \%)$ & \\
No Treatment & $8(26.7 \%)$ & \\
\hline BMI Body mas index, BASDA Bath Anky) & & \\
\hline
\end{tabular}

$B M I$ Body mass index, BASDAI Bath Ankylosing Spondylitis Disease Activity Index, BASFI Bath Ankylosing Spondylitis Functional Index, BASMI the Bath Ankylosing Spondylitis Metrology Index, BAS-G Bath Ankylosing Spondylitis Global Score, NSAID Non-steroidal anti-inflammatory drugs, DMARD Diseasemodifying anti-rheumatic drugs

$74.58 \mathrm{~g} / \mathrm{d}$ in AS group and $60.57 \mathrm{~g} / \mathrm{d}$ in healthy group $(p=0.02)$. Total energy and fat intake in patients group were significantly higher than the controls and total fat intake was weakly correlated with BASFI score of disease activity $(r=0.37 ; p=0.04)$ in the patient group.

Analysis of the lipid intake quality showed us that the consumption of Saturated fat (SF), mono unsaturated fatty acids (MUFA) and poly unsaturated fatty acids (PUFA) was significantly higher in AS patients compared to healthy controls and the intake of all the three components was moderately correlated with BASFI score and MUFA was also moderately correlated with BASMI score of patients (Table 6).

Interestingly the diet of studied AS patients contained satisfactory levels of vitamins and minerals as compared with recommended daily allowance [17, 18]. Patients' diets contained significantly more vitamins (A, B1, B2, C) and minerals (potassium, calcium, iron, phosphorus, magnesium, zinc, copper and selenium) compared to the diet of the control group (Tables 2,3,4). Vitamin $\mathrm{E}$ intake was moderately correlated to BASMI score in the patient group (Table 6).

The distribution of air pollution exposure in time intervals is shown in Table 5. There was no significant difference between cases and controls air pollution exposure in the time intervals studied.
Table 2 Dietary intake of food components in AS and healthy groups

\begin{tabular}{|c|c|c|c|}
\hline & $\begin{array}{l}\text { AS patients } \\
N=30 \text { mean (SD) }\end{array}$ & $\begin{array}{l}\text { Controls } \\
N=30 \text { mean }(S D)\end{array}$ & $\begin{array}{l}P \text {-value } \\
\text { t Test }\end{array}$ \\
\hline Energy (kj/d) & $2061.66(751)$ & $1652.18(551)$ & $0.02^{*}$ \\
\hline Carbohydrate (g/d) & 71.05 (22.8) & $63.35(22.6)$ & $0.02^{*}$ \\
\hline Protein (g/d) & $280.09(105)$ & $217.75(89)$ & 0.21 \\
\hline Fat $(\mathrm{g} / \mathrm{d})$ & $74.58(29.7)$ & $60.547(16.1)$ & $0.03^{*}$ \\
\hline Cholesterol (mg/d) & $211.59(130.7)$ & 206.75 (90.6) & 0.87 \\
\hline SF & $21.36(7.1)$ & $18.96(6.7)$ & $0.02^{*}$ \\
\hline MUFA & $26.04(12.5)$ & $19.55(6.5)$ & $0.018^{* *}$ \\
\hline PUFA & $18.82(8.7)$ & $13.83(3.8)$ & $0.007^{* *}$ \\
\hline Fiber (gr/d) & $29.53(23.4)$ & $19.56(16.5)$ & 0.07 \\
\hline
\end{tabular}

Mean concentration of PM 2.5 in the previous month before sampling was strongly correlated with BASFI, BASDI and BASMI score with $r=0.63, r=0.62$, and $r=$ 0.66 respectively and $p$-value was less than 0.05 Table 6 .

\section{Discussion}

The main purpose of our study was to find the relationship between environmental factors like diet and air pollution exposure with disease activity in a group of Iranian AS patients. There was a mild correlation between diet and disease activity, as assessed by BASFI and BASMI. This wasreflected by the results of the FFQ and nutritional calculations. Among all the essential components that were measured like proteins, the amount of carbohydrates, energy intake and fat intake in the patient group was significantly higher than the control group. In statistical analysis, only total fat intake, saturated fatty acids (SFA), mono unsaturated fatty acids (MUFA) and poly unsaturated fatty acids (PUFA) consumption was correlated with patient indices of disease, namely BASMI and BASFI.

Table 3 Dietary intake of vitamins in AS and healthy groups

\begin{tabular}{llll}
\hline Vitamins & $\begin{array}{l}\text { AS patients } \\
N=30 \text { mean (SD) }\end{array}$ & $\begin{array}{l}\text { Controls } \\
N=30 \text { mean }(S D)\end{array}$ & $\begin{array}{l}\text { P-value } \\
\text { t Test }\end{array}$ \\
\hline Vitamin A $(\mu \mathrm{g} / \mathrm{d})$ & $506.62(250.1)$ & $376.93(153.8)$ & $0.028^{*}$ \\
Vitamin C $(\mathrm{mg} / \mathrm{d})$ & $77.19(34.5)$ & $43.85(29.7)$ & $0.001^{* *}$ \\
Vitamin E (mg/d) & $11.22(6.05)$ & $7.01(2.5)$ & $0.001^{* *}$ \\
Vitamin B1 (mg/d) & $1.75(0.8)$ & $1.28(0.7)$ & $0.04^{*}$ \\
Vitamin B2 (mg/d) & $1.77(0.6)$ & $1.20(0.3)$ & $0.000^{* *}$ \\
Vitamin B3 (mg/d) & $20.23(8.5)$ & $16.09(8.8)$ & 0.84 \\
Vitamin B6 (mg/d) & $1.53(0.6)$ & $1.18(0.5)$ & $0.03^{*}$ \\
Vitamin B12 (mg/d) & $2.72(1.1)$ & $2.29(1.1)$ & 0.17 \\
\hline
\end{tabular}

*: $P$-value 0.01 to $0.05,{ }^{* *}: P$-value 0.001 to 0.01 
Table 4 Dietary intake of minerals in AS and healthy groups

\begin{tabular}{|c|c|c|c|}
\hline Minerals & $\begin{array}{l}\text { AS patients } \\
N=30 \text { mean (SD) }\end{array}$ & $\begin{array}{l}\text { Controls } \\
N=30 \text { mean (SD) }\end{array}$ & $\begin{array}{l}P \text {-value } \\
\text { t Test }\end{array}$ \\
\hline Sodium (g/d) & $2.497(1.6)$ & $2.00(1.4)$ & 0.25 \\
\hline Potassium (g/d) & $2.80(1.2)$ & $1.86(0.7)$ & $0.002^{* *}$ \\
\hline Calcium (mg/d) & $962.34(529.1)$ & $608.12(286.6)$ & $0.003^{* *}$ \\
\hline Iron (mg/d) & $22.72(18.1)$ & $11.76(6.0)$ & $0.004^{* *}$ \\
\hline Phosphorus (mg/d) & $1237.63(547.3)$ & $937.08(421.5)$ & $0.029^{*}$ \\
\hline Magnesium (mg/d) & $329.3(186.6)$ & $223.80(114.7)$ & $0.017^{*}$ \\
\hline $\operatorname{Zinc}(\mu \mathrm{g} / \mathrm{d})$ & $10.0(4.1)$ & $7.97(3.2)$ & $0.041^{*}$ \\
\hline Copper (mg) & $1.42(0.5)$ & $1.10(0.5)$ & $0.029^{*}$ \\
\hline Selenium (ug) & $135.87(62.2)$ & $103.26(40.7)$ & $0.029^{*}$ \\
\hline
\end{tabular}

Lipid components can directly or indirectly modify immune responses $[19,20]$, some toward pro-inflammatory and others immunosuppressive effects. Studies have shown that saturated fatty acids (SFA) play a key role in the inflammatory process by stimulating macrophage induction and the secretion of the pro-inflammatory cytokines TNF-alpha, IL-6, and IL-8 [21, 22]. Moreover, SFA intake can trigger IL- $1 \beta$ secretion and also is known to cause lipemia that is more noticeable than the lipemia due to mono unsaturated fatty acids (MUFA) and PUFA and can lead to a higher pro-inflammatory state [23].

However, monounsaturated fatty acid (MUFA) and polyunsaturated fatty acid (PUFA) consumption exhibit an anti-inflammatory profile and a less pronounced pro-inflammatory response particularly in comparison with SFAs, dietary polyunsaturated fatty acids (PUFA) like linoleic acid (LA; 18:2n6) can convert into arachidonic acid (AA; 20:4n6) by a series of enzymatic reactions which is a source of more proinflammatory eicosanoids, such as prostaglandin E2 (PGE2). Recently, SUNDSTRÖM et al. have shown the correlation between plasma phospholipid levels of AA and the BASDAI score in AS patients which can explain the results of our study more [24]. In concordance, we observed that higher consumptions of SFA were more strongly correlated with BASFI score than MUFA and PUFA. Recently, serum free fatty acids have been shown as a biomarker of AS and some evidence of fat metaplasia in the pathogenesis of this disease has been revealed $[25,26]$. Moreover, diet strongly influences the composition of the gut microbiota in this regards diet rich in fat and carbohydrates might impact the gut microbiota of AS patients thus subclinical gut inflammation in AS might restrict the absorption and despite high energy intake in AS, BMI is not higher than controls [27, 28].

Regarding FFQ results, most of vitamins and minerals that we measured had elevated intake levels in AS patients compared to control group, although we did not measure them in blood, this satisfactory level of vitamins and mineral consumption might be due to the willingness of the patients to improve their diseases. There is some evidence that AS patients have less vitamin A level in serum, despite higher intakes there might be some genetic polymorphisms or other reasons for poor absorption [29]. Therefore, it is highly recommended to measure dietary food components in blood to help a firm conclusion.

Our findings have shown that long term exposure (at least 1 month) to fine PM can exacerbate AS manifestations measured by BASDAI, BASFI and BASMI score. Air pollutants, especially particulate matters, can enter the body through the respiratory tract and deal with the immune system. PM10 includes a mixture of soil and road dust along with industrial emissions that makes coarse particles suspensions that is not small enough to penetrate to blood circulation and usually face with first responders immune cell types like dendritic cells and alveolar macrophages and could make local respiratory inflammations [30]. Whereas PM2.5 are mainly derived from combustion processes of diesel fuel, gasoline, and industrial processes and due to their tiny size they can pass the respiratory barriers and spread to the whole body through the bloodstream, therefore, are more associated with triggering systemic inflammations [31, 32]. Also the sustainability of pollutants and prolonged exposure to them could result in a chronic inflammation which provides a proper opportunity for unbalancing the $\mathrm{T}$ cell subsets toward Th1 and Th17 in a macrophage dependent fashion that can produce more elevated level of FN- $\gamma$, IL-10, IL-17 and IL-21 cytokines [33]. These activated $\mathrm{T}$ cells have shown to exacerbate the autoimmune disease conditions particularly in the AS [34]. However, many previous studies have shown that chronic inflammation plays

Table 5 Mean daily concentration of particulate matters exposure in time intervals in studied subjects

\begin{tabular}{|c|c|c|c|c|}
\hline \multirow[t]{2}{*}{ Day of sampling } & \multicolumn{2}{|l|}{ Case } & \multicolumn{2}{|l|}{ Control } \\
\hline & PM 2.5 g/m3- mean (SD) & Pm10 $\mu \mathrm{g} / \mathrm{m} 3$-mean (SD) & PM2.5 g/m3-mean (SD) & 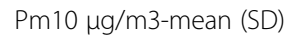 \\
\hline & $28.2(13.2)$ & $85.4(49.2)$ & $25.9(20.5)$ & $60.0(31.4)$ \\
\hline 1 month before sampling & $28.7(10.5)$ & $76.6(39.3)$ & $30.0(13.4)$ & $73.33(27.8)$ \\
\hline 3 months before sampling & $26.4(6.8)$ & 76.7 (36.6) & $27.6(9.2)$ & $67.44(11.38)$ \\
\hline
\end{tabular}


Table 6 Correlations between disease activity and environmental factors in AS patients

\begin{tabular}{llll}
\hline$n=30$ & $\begin{array}{l}\text { BASDAI Score } \\
\text { correlation coefficient } \\
(P \text { value })\end{array}$ & $\begin{array}{l}\text { BASFI Score } \\
\text { correlation coefficient } \\
(P \text {-value })\end{array}$ & $\begin{array}{l}\text { BASMI Score } \\
\text { correlation coefficient } \\
(P \text {-value })\end{array}$ \\
\hline Total fat of food & NS & $0.37(0.04)$ & NS \\
SF & NS & $0.43(0.01)$ & NS \\
MUFA & NS & $0.36(0.04)$ & $0.39(0.03)$ \\
PUFA & NS & $0.37(0.04)$ & NS \\
Vitamin E & NS & NS & $0.42(0.02)$ \\
PM2.5 in the 1 month before sampling & $0.63(0.03)$ & $0.62(0.04)$ & $0.66(0.02)$ \\
\hline
\end{tabular}

SF Saturated fat of food, MUFA Mono unsaturated fatty acids, PUFA Poly unsaturated fatty acids, NS Not significant

an important role in the pathogenesis of AS, there is no evidence of air born particulate matters effect on AS disease activity. Therefore our findings in the strong correlation results between long term exposure to PM2.5 and clinical manifestations of AS patients reveal a new perspective to air pollution effects on AS.

\section{Conclusion}

We found a higher consumption of total energy and fat, higher intake of some vitamins (A, B1, B2, C) and minerals (potassium calcium iron phosphorus magnesium zinc copper and selenium) in AS patients compared to controls. This can be due to the fact that patients are more aware of the effect of nutrition and they try to have a better diet. Fat component intake, especially Saturated Fat of Food was moderately correlated with BASFI score. This might be a field for further research and intervention in patients. Although air pollution exposure were not different among patients and controls, PM2.5 long term exposure was strongly correlated with BASMI, BASFI and BASDAI score of disease in the patient group. Living in areas with lower air pollution might be a solution for AS patients.

\section{Acknowledgements}

We thank Maryam Chamari for excellent FFQ analysis.

\section{Funding}

This research is supported by grants from Tehran University of Medical sciences (TUMS); Grant No.26052. There is no conflict of interest to declare.

\section{Availability of data and material}

Data and materials of this article are available by request email to nsoleimanifar20@gmail.com.

\section{Authors' contributions}

NS performed the experimental work, data analysis and wrote the manuscript, MN conceived the idea and co-supervised the project, KB designed the study and reviewed and corrected the manuscript, AJ evaluated patients and confirmed their disease, MM acquisition of patients' clinical data and revised the manuscript, SHM and NS analyzed and interpreted the data, $\mathrm{ZH}$ and NS contributed to the air quality control data collection, BN supervised the project, obtained funds. All authors were involved in the final approval of the manuscript.
Ethics approval and consent to participate

This research has been approved by Tehran University of Medical Sciences ethics committee; reference number IR.TuMS.REC.1394.439.

\section{Consent for publication}

Not applicable.

\section{Competing interests}

The authors declare that they have no competing interests.

\section{Publisher's Note}

Springer Nature remains neutral with regard to jurisdictional claims in published maps and institutional affiliations.

\section{Author details}

${ }^{1}$ Molecular immunology research center, Tehran University of Medical Sciences, Tehran, Iran. ${ }^{2}$ Department of Molecular Medicine, School of Advanced Technologies in Medicine, Tehran University of Medical Sciences, Tehran, Iran. ${ }^{3}$ Department of Immunology, Tehran University of Medical Sciences, Tehran, Iran. ${ }^{4}$ Immunology, Asthma and Allergy Research Institute, Tehran University of Medical Sciences, Tehran, Iran. ${ }^{5}$ Rheumatology Research Center, Tehran University of Medical Sciences, Tehran, Iran. ${ }^{6}$ Department of Community Medicine, Faculty of Medicine, Kermanshah University of Medical Sciences, Kermanshah, Iran.

Received: 17 July 2018 Accepted: 30 January 2019

Published online: 18 February 2019

\section{References}

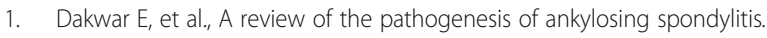
2008.

2. Raychaudhuri SP, Deodhar A. The classification and diagnostic criteria of ankylosing spondylitis. J Autoimmun. 2014;48:128-33.

3. Dean LE, et al. Global prevalence of ankylosing spondylitis. Rheumatology. 2014:53(4):650-7.

4. Shiue I. Relationship of environmental exposures and ankylosing spondylitis and spinal mobility: US NHAENS, 2009-2010. Int J Environ Health Res. 2015; 25(3):322-9.

5. Fallahi $\mathrm{S}$, et al. The correlation between pack-years of smoking and disease activity, quality of life, spinal mobility, and sacroiliitis grading in patients with ankylosing spondylitis. Turk J Rheumatol. 2013;28(3):181-8.

6. Soleimanifar $\mathrm{N}$, et al. Study of programmed cell death 1 (PDCD1) gene polymorphims in Iranian patients with ankylosing spondylitis. Inflammation. 2011;34(6):707-12.

7. Organization, W.H, Global health risks: mortality and burden of disease attributable to selected major risks. 2009: World Health Organization.

8. Bernatsky $\mathrm{S}$, et al. Fine particulate air pollution and systemic autoimmune rheumatic disease in two Canadian provinces. Environ Res. 2016;146:85-91.

9. Hamra, G.B., et al., Outdoor particulate matter exposure and lung cancer: a systematic review and meta-analysis. 2014.

10. Hajer GR, van Haeften TW, Visseren FL. Adipose tissue dysfunction in obesity, diabetes, and vascular diseases. Eur Heart J. 2008;29(24):2959-71. 
11. Rayssiguier $Y$, et al. High fructose consumption combined with low dietary magnesium intake may increase the incidence of the metabolic syndrome by inducing inflammation. Magnes Res. 2006;19(4):237-43.

12. Linden SVD, Valkenburg HA, Cats A. Evaluation of diagnostic criteria for ankylosing spondylitis. Arthritis Rheumatol. 1984;27(4):361-8.

13. Garrett $\mathrm{S}$, et al. A new approach to defining disease status in ankylosing spondylitis: the Bath ankylosing spondylitis disease activity index. J Rheumatol. 1994;21(12):2286-91.

14. Bidad K, et al. Evaluation of the Iranian versions of the bath ankylosing spondylitis disease activity index (BASDAI), the bath ankylosing spondylitis functional index (BASFI) and the patient acceptable symptom state (PASS) in patients with ankylosing spondylitis. Rheumatol Int. 2012;32(11):3613-8.

15. Zochling J, Braun J. Quality indicators, guidelines and outcome measures in ankylosing spondylitis. Clin Exp Rheumatol. 2007;25(6):S147.

16. Yanık B, et al. Adaptation of the Bath ankylosing spondylitis functional index to the Turkish population, its reliability and validity: functional assessment in AS. Clin Rheumatol. 2005;24(1):41-7.

17. Intakes, I.o.M.S.C.o.t.S.E.o.D.R., Dietary reference intakes for thiamin, riboflavin, niacin, vitamin B6, folate, vitamin B12, pantothenic acid, biotin, and choline. 1998: National Academies Press (US).

18. Alaimo, K., et al., Dietary intake of vitamins, minerals, and fiber of persons ages 2 months and over in the United States: third National Health and nutrition examination survey, phase 1, 1988-91. Adv Data, 1994(258): p. 1-28.

19. Calder PC. Dietary fatty acids and lymphocyte functions. Proc Nutr Soc. 1998;57(04):487-502

20. Harbige LS, Fisher BA. Dietary fatty acid modulation of mucosally-induced tolerogenic immune responses. Proc Nutr Soc. 2001;60(04):449-56.

21. Rocha D, et al. Saturated fatty acids trigger TLR4-mediated inflammatory response. Atherosclerosis. 2016;244:211-5.

22. Chait A, Kim F. Saturated fatty acids and inflammation: who pays the toll? Am Heart Assoc. 2010

23. L'homme L, et al. Unsaturated fatty acids prevent activation of NLRP3 inflammasome in human monocytes/macrophages. J Lipid Res. 2013;54(11): 2998-3008.

24. Sundström B, et al. Plasma phospholipid fatty acid content is related to disease activity in ankylosing spondylitis. J Rheumatol. 2012;39(2):327-33.

25. Chen $R$, et al. Serum fatty acid profiles and potential biomarkers of ankylosing spondylitis determined by gas chromatography-mass spectrometry and multivariate statistical analysis. Biomed Chromatogr. 2015; 29(4):604-11.

26. Maksymowych WP, et al. Fat metaplasia and backfill are key intermediaries in the development of sacroiliac joint ankylosis in patients with ankylosing spondylitis. Arthritis Rheumatol. 2014;66(11):2958-67.

27. Xiao $L$, et al. High-fat feeding rather than obesity drives taxonomical and functional changes in the gut microbiota in mice. Microbiome. 2017:5(1):43.

28. Sundström B, Wållberg-Jonsson S, Johansson G. Diet, disease activity, and gastrointestinal symptoms in patients with ankylosing spondylitis. Clin Rheumatol. 2011:30(1):71-6.

29. O'Shea FD, et al. Retinol (vitamin a) and retinol-binding protein levels are decreased in ankylosing spondylitis: clinical and genetic analysis. J Rheumatol. 2007;34(12):2457-9.

30. Fujii T, et al. Interaction of alveolar macrophages and airway epithelial cells following exposure to particulate matter produces mediators that stimulate the bone marrow. Am J Respir Cell Mol Biol. 2002;27(1):34-41.

31. Ristovski ZD, et al. Respiratory health effects of diesel particulate matter. Respirology. 2012;17(2):201-12.

32. Zhang $Y$, et al. Effect of atmospheric PM2. 5 on expression levels of NF-KB genes and inflammatory cytokines regulated by NF-KB in human macrophage. Inflammation. 2018:41(3):784-94.

33. Ma Q-Y, et al. Exposure to particulate matter 2.5 (PM2. 5) induced macrophage-dependent inflammation, characterized by increased Th1/Th17 cytokine secretion and cytotoxicity. Int Immunopharmacol. 2017;50:139-45.

34. Rezaiemanesh A, et al. Immune cells involved in the pathogenesis of ankylosing spondylitis. Biomed Pharmacother. 2018;100:198-204.

\section{Ready to submit your research? Choose BMC and benefit from:}

- fast, convenient online submission

- thorough peer review by experienced researchers in your field

- rapid publication on acceptance

- support for research data, including large and complex data types

- gold Open Access which fosters wider collaboration and increased citations

- maximum visibility for your research: over $100 \mathrm{M}$ website views per year

At $\mathrm{BMC}$, research is always in progress.

Learn more biomedcentral.com/submissions 